Khudair A. Salman A1-Jumaili BDS, CES, DSc (Prof)

\author{
Baydaa A. Othman Al-Rawi \\ BDS, MSc (Assist Lect)
}

Ghaeth H. Yassen

BDS, MSc (Assist Lect)

\section{Evaluation of Mandibular Infiltration Compared to Mandibular Block Anes- thesia in Pediatric Dentistry}

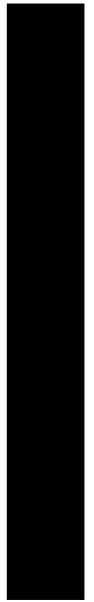

\author{
Dept of Pedod, Orthod and Prev Dentistry
}

College of Dentistry, University of Mosul

\begin{abstract}
Aims: The aim of this study is to determine the effectiveness of mandibular infiltration compared with the mandibular block in treating mandibular primary molars in children and to relate it to the type of treatment performed. Materials and Methods: The study design was case control study. The study sample consisted of 98 cooperative children of age 3-9 years old. Forty eight children were the study group (infiltration group). Equal number of children to the study group matched for age and gender were chosen (block group), they had the same criteria of the study group and required the same type of treatment. Dental procedure included amalgam restorations, foromcresol pulpotomies, and extractions. Evaluations of pain for each anesthesia technique and type of treatment were conducted using sounds; motor and ocular changes indicating pain. Evaluations were made upon probing, during tooth preparation, coronal pulp removal and extraction. Results: No statistically significant difference was found between the two anesthetic techniques of pain, when performing amalgam restorations ( $p>0.05)$. Mandibular infiltration was significantly less effective than mandibular block for pulpotomy and extraction $(p<0.05)$. Conclusions: In this study, the mandibular infiltration was found to be a reliable local anesthetic technique in amalgam restoration. For pulpotomy and extraction, mandibular infiltration was not as effective as mandibular block. It is recommended to avoid the mandibular infiltration anesthesia, whenever possible for pulpotomy or extraction procedure in primary molars.
\end{abstract}

Key Words: Mandibular infiltration, anesthesia, primary molars.

Al-Jumaili KA, Al-Rawi BA, Yaseen GH. Evaluation of Mandibular Infiltration Compared to Mandibular Block Anesthesia in Pediatric Dentistry. Al-Rafidain Dent J. 2009; 9(1):32-37.

Received: 29/11/2007_ Sent to Referees: 29/11/2007

Accepted for Publication: 5/2/2008

\section{INTRODUCTION}

Pain control is a mandatory part of dentistry and particularly of paediatric dentistry. Painful treatment has been shown to be important in the etiology of dental fear. ${ }^{(1)}$ The mandibular block is the local anesthetic technique of choice, when treating mandibular primary or permanent molars. Depth of anesthesia has been the primary advantage of this technique, while anesthesia of all molars, premolars and canines on the injected side allows for treating multiple teeth of the same quadrant at one appointment. ${ }^{(2)}$ Block anesthesia has some disadvantages for children, specifically the lengthy duration of the anesthesia which allows for the greater possibility of postoperative trauma, such as lip or tongue biting. Block is significantly more painful than buccal infiltra- tion, which sometimes affects the child's behavior. ${ }^{(3)}$ Furthermore, a successful mandibular block involves a degree of difficulty that makes the injection stressful for both the clinician and the patient. ${ }^{(4)}$

Investigations have looked at alternative techniques. Periodontal ligament injection delivered via a high-pressure syringe has been suggested as an alternative to the mandibular block. ${ }^{(5)}$ However, this type of injection may produce areas of hypoplasia or decalcification on the succedaneous teeth. ${ }^{(6)}$ Recently, a computerized local anesthetic delivery system (Wand) has been developed as a possible good alternative for the mandibular block in the lower primary molars and the complicated equipment required for this technique is the main disadvantage. ${ }^{(7,8)}$ 
Infiltration anesthesia has been used successfully to restore maxillary teeth but has been avoided in the mandibular molar regions because of denser bone that does not allow adequate dissemination of the anesthetic. Although not widely accepted, infiltration in the mandibular molar region of primary teeth has been suggested as another means of achieving anesthesia. There are advantages for using infiltration or supraperiosteal injection rather than a mandibular block. It is relatively easy to administer; it does not numb the tongue and lips; and it offers the possibility of a shorter anesthetic duration. ${ }^{(3)}$ A disadvantage is that it cannot be relied upon for complete anesthesia of mandibular primary molars. ${ }^{(9)}$

Several studies have evaluated the effectiveness of mandibular infiltration as a possible alternative to the mandibular block for the restoration of primary molars. No significant differences between infiltration and block were found. In addition, the quality of anesthesia was not significantly related to tooth location, age or type of anesthetic agent. ${ }^{(10,11)}$
Hence, the aim of this study was to determine the effectiveness of mandibular infiltration compared with mandibular block in treating the mandibular primary molars in children and relate it to the type of treatment performed.

\section{MATERIALS AND METHODS}

The study sample consisted of 98 children. The study design was a case control study. The groups were selected from the children who were treated at the Paediatric Department Clinic at the College of Dentistry, Mosul University to be included in the study group (infiltration group) the children should had the following criteria: (1) Age of children was between 3-9 years. ${ }^{(12)}$ (2) The children were healthy with no known allergies to medication or local anesthesia. ${ }^{(12)}$ (3) The children were cooperative at the initial visit. Rating 3 or 4 according to Frankle scale, Table (1), so that to allow for adjustment to dental environment and to confirm their cooperative behavior. ${ }^{(13)}$ (4) The children had carious lesion in mandibular primary molars requiring treatment. ${ }^{(12)}$

Table (1): Frankle behavior scale to measure cooperative behavior ${ }^{(13)}$

\begin{tabular}{|c|c|}
\hline & Definitely negative \\
\hline Rating 1 & $\begin{array}{l}\text { Refusal of treatment, crying forcefully, fearful, or any other over evidence of } \\
\text { extreme negativism. }\end{array}$ \\
\hline \multirow[b]{2}{*}{ Rating 2} & Negative \\
\hline & $\begin{array}{l}\text { Reluctant to accept treatment, uncooperative, some evidence of negative atti- } \\
\text { tude but not pronounced (i.e., sullen, withdrawn) }\end{array}$ \\
\hline & Positive \\
\hline Rating 3 & $\begin{array}{l}\text { Acceptance of treatment; at times cautious; willingness to comply with the } \\
\text { dentist, at times with reservation, but patient follows the dentist's directions } \\
\text { cooperatively. }\end{array}$ \\
\hline & Definitely positive \\
\hline Rating 4 & $\begin{array}{l}\text { Good rapport with the dentists interested in the dental procedures, laughing } \\
\text { and enjoying }\end{array}$ \\
\hline
\end{tabular}

Equal number of children in the study group (infiltration group) matched for age and gender were chosen for the control group (block group) that had the same criteria of the study group and required the same type of treatment.

The study group received infiltration anesthesia for the treatment of mandibular molars. The procedure was as follows: following 2 minutes application of topical anesthesia (lidocain $\mathrm{HCl} 2 \%$ medico, Syria) on dry mucosa, $1.7 \mathrm{ml}$ of lidocain hydrochloride $2 \%$ containing epinephrine 1:800,000 (Lignospan, France) was infiltrated in the mucobuccal fold between the roots of the tooth to be treated, a 27 gauge needle $11 \mathrm{~mm}$ long (Septodent, France) was used for all the infiltration injections. Five minutes waiting period elapsed before the teeth to be treated were probed buccally and lingually to determine anesthesia and the treatment procedure began, treatment was discontinued if the child expressed signs of pain and was resumed 
after a mandibular block was given, once the pain was evaluated during the dental procedure, the child was crossed over to a mandibular block. ${ }^{(12)}$

For the control group (block group), the mandibular block was performed using the conventional technique and $1.7 \mathrm{ml}$ of anesthesia, lidocain hydrochloride $2 \%$ containing epinephrine 1:800,000 (Lignospan, France). A long buccal nerve injection also was administered in all subjects as an adjunct to the mandibular block to guarantee anesthesia for the buccal mucosa. A 27 gauge needle 25mm long (Septodent, France) was used for the block injection.

Dental procedures included class I and II amalgam restorations, formocresol pulpotomies and extraction. Effectiveness of each anesthesia technique was assessed by evaluating the presence or absence of pain while probing the gingival, during the use of high and low speed hand piece and during extraction. A separated evaluation was made during the removal of the coronal pulp during a pulpotomy procedure. Any sign of discomfort indicating pain upon assessment of each evaluation interval was recorded as a presence of pain. The procedure was discontinued and the anesthesia technique evaluated as inadequate.

Signs of discomfort included hand and body tension, eye movements indicating pain, verbal complaints, tears, hand and body movements, no observational scale to quantitate discomfort was used. Either there was discomfort or not and that was translated to presence or absence of pain. (12)

The z-test was used for the statistical analysis of pain evaluation, the test was performed with one degree of freedom, at 0.05 level of significance.

\section{RESULTS}

A total of 98 children participated in the study, 49 subject were the study group (infiltration group), and the same number of subjects for the control group (block group). Both of the groups consisted of 28 male and 21 female as shown in Table (2). The mean age of each group was 5.3 years.

Table (2): Distribution of study and control group according to gender

\begin{tabular}{lccc}
\hline \multicolumn{1}{c}{ Group } & Male & Female & Total \\
\hline $\begin{array}{l}\text { Study } \\
\text { group }\end{array}$ & 28 & 21 & 49 \\
$\begin{array}{l}\text { Control } \\
\text { group }\end{array}$ & 28 & 21 & 49 \\
\hline
\end{tabular}

A total of 30 amalgam fillings (14 class I amalgam restoration and 16 class II amalgam restorations) were completed in both groups. Thirty fomocresol pulpotomy were completed in the primary molars of the two groups, while 38 teeth were extracted as shown in Table (3).

When class I or II amalgam restoration on the first or second primary molars was performed, no significant difference in children pain response between the two techniques was found ( $p>0.05$ ) upon probing or during cavity preparation as illustrated in Table (4).

Table (3): Distribution of dental procedures performed to the study and control groups

\begin{tabular}{lcccc}
\hline \multicolumn{2}{c}{ Group } & Study group & Control group & Total \\
\hline Amalgum & Class I & 7 & 7 & 30 \\
filling & Class II & 8 & 8 & \\
Formocresol pulpotomy & 15 & 15 & 30 \\
Extraction & 19 & 19 & 38 \\
\hline
\end{tabular}


Table (4): Pain assessment for mandibular infiltration (study group) and block anesthesia (control group) during restorative treatment

\begin{tabular}{lcccc}
\hline $\begin{array}{c}\text { Pain evaluation } \\
\text { intervals }\end{array}$ & Study group & $\begin{array}{c}\text { Control } \\
\text { group }\end{array}$ & z- value & p-value \\
\hline Probing & $1 / 15$ & $0 / 15$ & 1.04 & 0.301 \\
Preparation & $2 / 15$ & $1 / 15$ & 0.61 & 0.54 \\
\hline
\end{tabular}

- Results are expressed in number of teeth with pain compliant out of total number of teeth treated.

When performing a formocresol pulpotomy, the mandibular infiltration anesthesia (study group) did not provide adequate anesthesia and there was a significant difference during coronal pulp removal between the two techniques $(\mathrm{p}<0.05)$, while no significant difference was reported upon probing or during cavity preparation $(\mathrm{p}>0.05)$ as shown in Table (5).
When performing extraction, no significant difference was noted upon probing between the two injections techniques ( $>>0.05)$, while there was a significant difference between the two technique during extraction $(\mathrm{p}<0.05)$ as more children experienced pain when mandibular infiltration was given as explained in Table (6).

Table (5): Pain assessment for mandibular infiltration (study group) and block anesthesia (control group) during pulpotomy treatment

\begin{tabular}{lcccc}
\hline \multicolumn{1}{c}{\begin{tabular}{c} 
Pain evaluation \\
\multicolumn{1}{c}{ intervals }
\end{tabular}} & Study group & Control group & z-value & p-value \\
\hline Probing & $1 / 15$ & $0 / 15$ & 1.04 & 0.301 \\
$\begin{array}{l}\text { Preparation } \\
\begin{array}{l}\text { Coronal pulp am- } \\
\text { putation }\end{array}\end{array}$ & $2 / 15$ & $0 / 15$ & 1.52 & 0.129 \\
\hline
\end{tabular}

- Results are expressed in number of teeth with pain compliant out of total number of teeth treated. * Statistically significant difference $p<0.05$.

Table (6): Pain assessment for mandibular infiltration (study group) and block anesthesia (control group) during extraction.

\begin{tabular}{lcccc}
\hline $\begin{array}{c}\text { Pain evaluation } \\
\text { intervals }\end{array}$ & Study group & Control group & z-value & p-value \\
\hline Probing & $1 / 19$ & $0 / 19$ & 1.01 & 0.311 \\
Extraction & $2 / 19$ & $7 / 19$ & 2.01 & $0.045^{*}$ \\
\hline
\end{tabular}

- Results are expressed in number of teeth with pain compliant out of total number of teeth treated. * Statistically significant difference $\mathrm{p}<0.05$.

\section{DISCUSSION}

Mandibular infiltration has been questioned as an adequate anesthesia technique in the treatment of the primary molars. ${ }^{(9)}$
Results indicated that the mandibular infiltration is an effective technique when performing an amalgam restoration in the primary molar. This is in agreement with other researchers ${ }^{(10-12)}$. The 
establishment of anesthesia after the mandibular infiltration has been attributed to the dissemination of a local anesthesia through the mandibular bone.

The mandibular infiltration technique was significantly more painful compared to the mandibular block during pulpotomy procedure. This is in agreement with Oulis et $\mathrm{al}^{(12)}$ and Sharaf ${ }^{(14)}$, but disagreed with the results of Dudkiewiewicz et al. ${ }^{(10)}$ The use of different local anesthetic, infiltration at each root of the molar to be restored, waited for a period of ten minutes before undertaking the procedure, as well as the smaller sample size without a comparison block in Dudkiewiewicz et al. ${ }^{(10)}$ study can account for the disagreement with the result in this study.

Regarding extraction, there was significant difference between the two techniques as mandibular infiltration couldn't be considered to be as reliable in the extraction procedure, this is contraction with results of other authors ${ }^{(12,14)}$ and could be attributed to the small sample size. The presence of a periapical abscess that makes dissemination of the anesthesia difficult and the absorption slow. The degree of root resorption and the degree of tooth destruction are all factors that may be responsible for this disagreement.

No attempt was made in this project to study the relationship of the anesthesia established to the age of the subject, because of the small sample size of this study. Furthermore, all the previous studies failed to show any significant difference between the child's age and the anesthesia established. ${ }^{(3,12)}$

To avoid difference in anesthesia quality from using different local anesthetics and to make results more comparable. We selected lidocain 2\% 1:800:000 epinephrine, a local anesthetic that is widely accepted and used in dentistry. Wright et al. $^{(3)}$ used various local anesthetics but failed to show any significant difference in the anesthesia effectiveness although the potency of anesthesia differed markedly.

\section{CONCLUSIONS}

Mandibular infiltration has been routinely avoided in treating mandibular molars, because of its questionable adequacy. In this study, mandibular infiltration was found to be reliable local anesthetic technique in amalgam restoration, but for pulpotomy and extraction, mandibular infiltration was not as effective as mandibular block, it is recommended to avoid mandibular infiltration anesthesia whenever possible for pulpotomy or extraction procedure in primary molars.

\section{REFERENCES}

1. Nakai Y, Milgrom P, Mancel L, Coldwell S, Domoto P, Ramsay D. Effectiveness of local anesthesia in pediatric dental practice. JADA. 2000; 131: 16991705.

2. Ram D and Pertez B. Administering local anesthesia to paediatric dental patients- current status and prospects for the future. Int J Paediat Dent. 2002; 12:80-89.

3. Wright GZ, Weinberger SJ, Marti R, Plotzke O. The effectiveness of infiltration anesthesia in the mandibular primary molar region. Pediat Dent. 1991; 13: 278-283.

4. Shields PW. Further observation on mandibular anesthesia. Aust Dent $J$. 1977; 22: 334-338.

5. Davidson L and Craig S. The use of periodontal ligament injection in children. J Dent. 1987; 5:204-208.

6. Branstorm M, Lindskog S, Nodenvall K. Enamel hypoplasia in permanent teeth induced by periodontal ligament anesthesia of primary teeth. JADA. 1984; 109: 735-736.

7. Asarah T, Allen K, Petersen B, Beiraghi S. Efficacy of a computerized local anesthesia device in pediatric dentistry. Pediat Dent. 1999; 21: 421-424.

8. Ashkenazi M, Blumer S, Eli I. Effectiveness of computerized delivery of intrasulcular anesthetic in primary molars. JADA. 2005; 136: 1418-1425.

9. McDonald RE., Avery DR., Dean J. Local anesthesia for the child and adolescent. In: McDonald RE., Avery DR., eds. Dentistry for the child and adolescent. 7th edition, Chapter.13, St. Louis: Mosby; 2000.P. 274.

10. Dudkiewicz A, Schwartz S, Laliberte R. Effectiveness of mandibular infiltration in children using the local anesthetic Ul- 
tracaine (articaine hydrochloride). $\mathrm{J} \mathrm{Ca}$ nad Dental Assoc. 1987; 53: 29-31.

11. Donohue D., Garcia-Godoy F., King DL, Barnwell GM. Evaluation of mandibular infiltration versus block anesthesia in pediatric dentistry. J Dent Child, 1993; 60: 104-106.

12. Oulis CJ, Vadiakas GP, Vasilopoulou A. The effectiveness of mandibular infiltration compared to mandibular block anes- thesia in treating primary molars in children. Pediat Dent. 1996; 18: 301-305.

13. Frankl SN, Shiere FR, Fogels HR. Should the parent remain with the Child in the dental operatory. $J$ Dent Child. 1962; 29: 150-163.

14. Sharaf AA: Evaluation of mandibular infiltration versus block anesthesia in pediatric dentistry. J Dent Child. 1997; 64: 276-281. 